and their relationship to pathogenesis of disease ${ }^{B}$ will be an interesting challenge.

FREDERICK ALADJ
Gates and Crellin Laboratories of Chemistry, California Institute of Technology, Pasadena, and

Department of Medical Microbiology, University of Southern California School of Medicine, Los Angeles, California.

Dan H. Campbelt

Gates and Crellin Laboratories of Chemistry, California Institute of Technology, Pasadena.

Alarjem, F., Lieberman, M., and Gofman, J. W., J. Exp. Med. [105. $49(1957)]$.

Oudin, J., "Methods of Medical Research", 5, 335 (The Year Book Publishers, Inc., 1952)

" Korngold, L., and Lipari, R., Science, 121, 170 (1955).

4 Levine, L., Kauffman, D. L., and Brown, R. K., J. Exp. Med., 102, 105 (1955).

'Ouchterlony, O., Acta Pathol., 32, 231 (1953).

- Gofman, J. W., et al., Plasma, \&, 413 (1954).

\section{Motile Catalase-producing Strains of Lactobacillus delbrückii}

The characteristics of the lactic fermentationinducing bacteria used for lactic acid production in several industrial plants in Czechoslovakia known under the name Lactobacillus delbrückii have been investigated. Several significant differences from the description of this species in Bergey's "Manual" have been found, though the fermentation of sugars and the production of lactic acid were in accord with the data given. A surprising catalase content, however, has been revealed.

Quantitative catalase determination by means of the Warburg respirometer ${ }^{1}$ has shown a catalase content in all the strains investigated. The catalase quotient has been found to be 2,000 at $p \mathrm{H} 7$ and at the incubation temperature $37^{\circ} \mathrm{C}$., so that it is near Escherichia coli $(2,100)$. Besides catalase the spectrophotometric investigation revealed the presence of cytochrome $a$ and $b$. The cytochrome $c$ zone was indistinet. 'The presence of the hrematin pigments has been checked by the inhibitory effect of potassium cyanide on glucose oxidation.

The purity of the strains has been checked by means of the dilution method, by isolation from one cell and by means of a selective culture medium. It has been concluded that the observed differences in the enzymatic systems of the strains studied, disagreeing with the usual descriptions of Lactobacillus delbrückii, can be in no case explained by an infection or lack of homogeneity of the strain.

It is assumed that the strains investigated are similar in their characteristics to Thermobacterium cereale as described by Davis ${ }^{2}$. In text-books Thermobacterium cereale is usually erroneously considered to be a synonym for Lactobacillus delbrïckii.

Contrary to the characteristics commonly ascribed to the genus Lactobacillus we have observed flagella in two of the strains. The only observations of this phenomenon in the literature are those by Harrison and Hansen ${ }^{3}$ in Lactobacillus plantarum var. mobilis, by Mann and Oxford ${ }^{4}$ in three unstable cultures of Lactobacillus isolated from the rumens of calves and by Cunningham and Smith (quoted from Tittsler et $\left.a l .{ }^{5}\right)$ in the Lactobacillus isolated from silage. Electron microscopic observation has revealed long

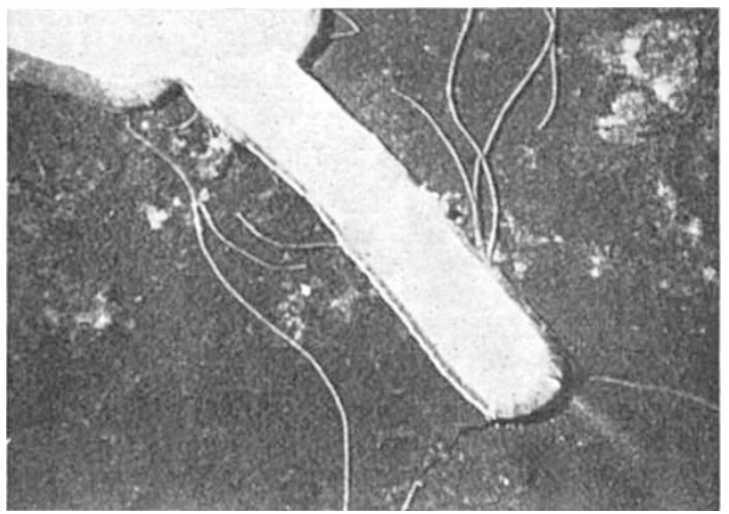

Fig. 1. Electronmicrograph of Lartobarillus delbrückii from $48^{\circ}$ C., $8 \mathrm{hr}$., malt agar culture, shuwing flagella. ( $x$ c. 18,500)

flagella (Fig. 1) in young cells 7-9 hr. old from two of the three strains investigated. In the third strain no flagellum could be found.

Department of General Microbiology,

Jiřina VAŇKOVA*

Charles University,

Prague. Nov. 2.

- Present address : Biological Institute of the Czechoslovak Academy of Science, Prague.

${ }^{1}$ Fujita, A., and Kodama, T., Biochem. Z., 232, 20 (1931).

Davis, J. G., Biochem. Z., 265, 90 (1933).

Harrison, jun., A. P., and Hansen, P. A., J. Bact., 59, 444 (1950). - Mann, S. O., and Oxford, A. E., J. Gen. Microbiol., 11, 83 (1954).

- Tittsler, R. P., Pederson, C. S., Snell, E. E., Hendlin, D., and Niven,

Ch. F., Bact. Rev., 16, 227 (1952).

\section{Host Infection in Pellicularia flamentosa controlled by Chemical Stimuli}

Pathogenic specificity of different strains of the fungus Pellicularia filamentosa (Pat) Rogers to different host plants has been shown by Flentje ${ }^{1}$ to be determined at two distinct stages in the infection process. One of these stages is on the external surface of the host stem before penetration occurs. The hyphæ of a pathogenic strain become attached to the cuticle of a susceptible host above the junction of epidermal cells, grow in a characteristic manner along the stem following the lines of junction of these cells, and form complex appressoria or 'infection cushions'. Each infection cushion is produced from a side branch in which normal elongation has ceased but in which further prolific side branching has occurred. Infection takes place only from these cushions. Strains not pathogenic to the host fail to become attached to or organize on the stems. Flentje ${ }^{1}$ suggested that this differential reaction may be due to a diffusible chemical exudation from the host.

The first direct evidence of stimulation of $P$. filamentosa by chemical exudates from seedlings was presented by Kerr ${ }^{2}$ using a 'Cellophane' bag technique. This work has been extended by us, using several distinct strains of the fungus and three types of seedling-radish, tomato and lettuce. In several tests there was a close correlation between the susceptibility of the seedlings to the pathogens and the stimulation of the pathogens by the seedlings. It was apparent that a root excretion was causing this differential stimulation of growth of the different strains. Most strains of $P$. filamentosa cause a damping-off of seedlings, the roots of which are not attacked by the fungus, but it was thought that excretions 